\title{
GST-omega genes interact with environmental tobacco smoke on adult level of lung function
}

\author{
Kim de Jong ${ }^{1,3}$, H Marike Boezen ${ }^{1,3}$, Nick HT ten Hacken ${ }^{2,3}$, Dirkje S Postma ${ }^{2,3}$, Judith M Vonk ${ }^{1,3^{*}}$ \\ and the LifeLines cohort study
}

\begin{abstract}
Background: Lung growth in utero and lung function loss during adulthood can be affected by exposure to environmental tobacco smoke (ETS). The underlying mechanisms have not been fully elucidated. Both ETS exposure and single nucleotide polymorphisms (SNPs) in Glutathione S-Transferase (GST) Omega genes have been associated with the level of lung function. This study aimed to assess if GSTO SNPs interact with ETS exposure in utero and during adulthood on the level of lung function during adulthood.
\end{abstract}

Methods: We used cross-sectional data of 8,128 genotyped participants from the LifeLines cohort study. Linear regression models (adjusted for age, sex, height, weight, current smoking, ex-smoking and packyears smoked) were used to analyze the associations between in utero, daily and workplace ETS exposure, GSTO SNPs, the interaction between ETS and GSTOs, and level of lung function (FEV $1, \mathrm{FEV}_{1} / \mathrm{FVC}$ ). Since the interactions between ETS and GSTOs may be modified by active tobacco smoking we additionally assessed associations in never and ever smokers separately. A second sample of 5,308 genotyped LifeLines participants was used to verify our initial findings.

Results: Daily and workplace ETS exposure was associated with significantly lower FEV 1 levels. GSTO SNPS (recessive model) interacted with in utero ETS and were associated with higher levels of FEV ${ }_{1}$, whereas the interactions with daily and workplace ETS exposure were associated with lower levels of FEV ${ }_{1}$, effects being more pronounced in never smokers. The interaction of GSTO2 SNP rs156697 with in utero ETS associated with a higher level of FEV 1 was significantly replicated in the second sample. Overall, the directions of the interactions of in utero and workplace ETS exposure with the SNPs found in the second (verification) sample were in line with the first sample.

Conclusions: GSTO genotypes interact with in utero and adulthood ETS exposure on adult lung function level, but in opposite directions.

Keywords: Genes, Environmental tobacco smoke, Lung function

\section{Background}

Lung function loss is common in chronic respiratory diseases like chronic obstructive pulmonary disease (COPD), cystic fibrosis (CF) and interstitial lung fibrosis, and associates with all-cause and other specific mortality $[1,2]$. Both environmental and genetic factors contribute to lung function loss. Active cigarette smoking is regarded as the most important environmental risk factor, yet other

\footnotetext{
* Correspondence: j.m.vonk@umcg.nl

${ }^{1}$ University of Groningen, University Medical Center Groningen (UMCG),

Department of Epidemiology, Groningen, the Netherlands

${ }^{3}$ University Medical Center Groningen, Groningen Research Institute for

Asthma and COPD (GRIAC), Groningen, the Netherlands

Full list of author information is available at the end of the article
}

factors exist. Like active smoking, passive cigarette smoking or environmental tobacco smoke (ETS) exposure induces inflammation and oxidative stress in the lungs [3]. ETS exposure has been associated with reduced level of lung function at birth $[4,5]$ and in adulthood [6,7], as well as with respiratory symptoms $[8,9]$ and increased COPD risk $[10,11]$. In other words, ETS exposure can affect in utero lung development, lung growth during childhood and lung function loss during adulthood. However, the underlying mechanisms have not been elucidated. Furthermore, these underlying mechanism are not necessarily similar for ETS exposure in utero and during adulthood

\section{Biomed Central}


given the fact that both the mode of exposure and the period of exposure within the life-span are different.

Although it has been very well established that genetic factors contribute to lung function level [12], less is known about how genetic factors modify effects of ETS exposure on the level of lung function during the life-span. Glutathione S-Transferases (GSTs) are a family of enzymes involved in the detoxification of xenobiotic substances such as tobacco smoke, and play an essential role in oxidative stress reactions [13,14]. Polymorphisms in the GST-mu, - $p i$, and -theta genes have been described to interact with tobacco smoke exposure with respect to asthma development and atopy in asthmatic children [15,16] and lower childhood level of lung function [17]. The GST-omega (GSTO) class has been less well studied. Of interest, GSTO enzymes have thioltransferase activity and can catalyze specific reduction reactions with compounds that are not substrates for other GSTs, suggesting an important role for GSTO in oxidative stress reactions $[18,19]$ and in biotransformation of inorganic arsenic [20], a component present in tobacco smoke. GSTO1 has also been reported to activate IL-1 $\beta$ [21], a cytokine that is important for tobacco smoke induced inflammation and fibrosis $[22,23]$. Harju et al. showed that GSTO1 is abundantly expressed in alveolar macrophages [24]. Furthermore, a genome wide association analysis in the Framingham Heart Study found a GSTO2 SNP (rs156697) to be associated with both lower level of $\mathrm{FEV}_{1}$ and FVC [12]. Another study could not replicate this association between $\mathrm{rs} 156697$ and $\mathrm{FEV}_{1}$, but found an association with COPD, defined by lower lung function [25]. It is unknown whether GSTO1 and GSTO2 SNPs modify effects of ETS exposure on the level of lung function.

This study aimed to assess if GSTO SNPs interact with in utero and/or adulthood ETS exposure on lung function level in a general population.

\section{Methods}

\section{Study sample and measurements}

We included 8,128 genetically unrelated individuals from the LifeLines cohort study. The LifeLines cohort is designed to investigate universal risk factors and their modifiers for multifactorial chronic diseases and comorbidities [26]. All subjects received a questionnaire and underwent a medical examination including collection of a blood sample for DNA extraction. The questionnaire included questions regarding personal characteristics, smoking habits and ETS exposure. We used self-reported in utero ETS exposure (coded as: no/yes/do not know), daily ETS exposure based on self-reported hours of exposure to other person's tobacco smoke per day (coded as: $<1 / \geq 1$ hour per day), and ETS exposure at work (answer categories: no/yes/not applicable). The medical examination included spirometry $\left(\mathrm{FEV}_{1}\right.$ and $\left.\mathrm{FEV}_{1} / \mathrm{FVC}\right)$ performed in a standardized setting following ATS guidelines using a Welch Allyn Version 1.6.0.489, PC-based SpiroPerfect with CardioPerfect Workstation software. A second sample, including 5,308 individuals from the LifeLines cohort study genotyped at a later stage, was used to verify our initial findings. Questionnaires, medical examinations and genotyping at baseline were performed according to the same standardized protocol in sample 1 and sample 2 .

\section{Genotyping}

Genotyping was performed using IlluminaCytoSNP-12 arrays. Beagle (version 3.3) and the HapMap3-database were used to impute additional SNPs. Three Haplotypetagging SNPs in the GSTO1-2 cluster with minor allele frequency $(\mathrm{MAF})>0.1, \mathrm{HW}$-equilibrium $\mathrm{p}$-value $>0.05$, and $\mathrm{R}^{2}<0.8$ were selected with Haploview (version 4.2). We additionally included SNP rs156697 that was associated with lower $\mathrm{FEV}_{1}$ and FVC in the Framingham Heart Study [12]. The four selected SNPs were rs4925, rs1147611, rs156697 and rs156699. LD-plot (Additional file 1: Figure S1) and genotype frequencies (Additional file 1: Table S1) are presented in the online supplement.

\section{Statistical analysis}

Linear regression models adjusted for age, sex, height, weight, current smoking, ex-smoking, and packyears smoked, were used to analyze the associations between ETS exposure, GSTO SNPs, the interaction between ETS and GSTOs and level of lung function $\left(\mathrm{FEV}_{1}, \mathrm{FEV}_{1} / \mathrm{FVC}\right)$. Since the interactions between ETS and GSTOs may be modified by active tobacco smoking we additionally assessed associations in never and ever smokers separately. All analyses were performed using SPSS version 20.0 (IBM Corporation, USA). P-values $<0.05$ (tested 2-sided) were considered statistically significant. To examine the robustness of our findings we used False Discovery Rate (FDR) correction for multiple testing [27], taking into account the number of tests performed for each of the exposures (4 SNPs * 3 separate analyses (all/never/ever) * 2 outcomes $\left(\mathrm{FEV}_{1}, \mathrm{FEV}_{1} / \mathrm{FVC}\right)$ ).

\section{Ethical approval}

The study was approved by the Medical Ethics Committee of the University Medical Center Groningen, Groningen, The Netherlands (ref. METc 2007/152).

\section{Results}

\section{Population characteristics}

Characteristics of both samples 1 and 2 are shown in Table 1. Briefly, both samples included more females than males and more ever than never smokers. $15 \%$ of the participants did not know whether their mother smoked during pregnancy, and this group was excluded in the analyses on the effect of in utero exposure on the 
Table 1 Characteristics participants included in sample 1 and sample 2

\begin{tabular}{|c|c|c|}
\hline & Sample 1 & $\begin{array}{c}\text { Sample } 2 \\
\text { (verification) }\end{array}$ \\
\hline $\mathbf{n}$ & 8128 & 5308 \\
\hline Males, n (\%) & $3483(43)$ & $2133(40)$ \\
\hline Age, median (min-max) & $47(18-89)$ & $48(21-90)$ \\
\hline \multicolumn{3}{|l|}{ Smoking status, $\mathrm{n}(\%)$} \\
\hline Never, n (\%) & $3277(40)$ & $2154(41)$ \\
\hline Ex, n (\%) [median (min-max)] & $\begin{array}{l}2882(36) \\
{[8(0-86)]}\end{array}$ & $\begin{array}{c}2014(39) \\
{[7(0-100)]}\end{array}$ \\
\hline Current, n (\%) [median (min-max)] & $\begin{array}{c}1936(24) \\
{[15(0-100)]}\end{array}$ & $\begin{array}{c}1065(20) \\
{[16(0-81)]}\end{array}$ \\
\hline \multicolumn{3}{|l|}{ ETS exposure, $n(\%)$} \\
\hline In utero & $867(13)$ & $559(13)$ \\
\hline$\geq 1$ hour/day & $1788(24)$ & $1029(21)$ \\
\hline At the workplace & $565(7)$ & $303(6)$ \\
\hline \multicolumn{3}{|l|}{ Lung function, mean (sd) } \\
\hline $\mathrm{FEV}_{1}(\mathrm{ml})$ & $3412(831)$ & $3331(840)$ \\
\hline $\mathrm{FEV}_{1} \mathrm{pp}(\%)^{1}$ & $102(14)$ & $102(14)$ \\
\hline $\mathrm{FEV}_{1} / \mathrm{FVC}(\%)$ & $77(7)$ & $76(7)$ \\
\hline Spirometry available, $n$ & 7635 & 5070 \\
\hline
\end{tabular}

The second sample (sample 2) was used to verify the initial findings from sample 1, both samples are part of the LifeLines population-based cohort study.

${ }^{1} \mathrm{FEV}_{1} \mathrm{pp}=\mathrm{FEV}_{1}$ as percentage predicted based on reference equations constructed by Quanjer et al. [28].

level of lung function. Of the remaining participants, $13 \%$ reported in utero ETS exposure. Almost $25 \%$ of the participants reported daily ETS exposure ( $\geq 1$ hours), and $7 \%$ reported ETS exposure at the workplace (in 12\% of the participants this was not applicable because of unemployment; this group was coded as a separate category in the analyses). The median level of self-reported exposure was 2 hours per day within the group with daily ETS exposure (25th percentile $=1$ hour, 75 th percentile $=4$ hours).

\section{ETS exposure and level of lung function}

Complete data on all covariates was available for $n=6003$, 6822 and 7149 subjects for in utero ETS exposure (excluding 'do not know'), daily and workplace ETS exposure respectively. In utero ETS exposure was not associated with $\mathrm{FEV}_{1}$ and was negatively associated with $\mathrm{FEV}_{1} / \mathrm{FVC}[\mathrm{b}=-0.6 \%(95 \% \mathrm{CI}=-1.1 ;-0.1)]$. The association with $\mathrm{FEV}_{1} / \mathrm{FVC}$ was similar for never and ever smokers (Additional file 1: Table S2). Daily ETS exposure ( $\geq 1$ hour) was significantly associated with lower $\mathrm{FEV}_{1}$ [-37 $\mathrm{ml}(-65 ;-8)]$, and not with $\mathrm{FEV}_{1} / \mathrm{FVC}$. Workplace ETS exposure was significantly associated with lower $\mathrm{FEV}_{1}[-43 \mathrm{ml}(-86 ; 0)]$, and $\mathrm{FEV}_{1} / \mathrm{FVC}[-0.6 \%(-1.2 ; 0)]$. Stratification by smoking status resulted in significant associations of ETS exposure with $\mathrm{FEV}_{1}$ in never smokers only, effect estimates being $-45 \mathrm{ml}(-91 ; 0)$ and $-82 \mathrm{ml}$
$(-153 ;-11)$ for daily and workplace ETS respectively (Figure 1). Daily and workplace ETS exposure were not significantly associated with $\mathrm{FEV}_{1} / \mathrm{FVC}$ in never or ever smokers (for all effect estimates see Additional file 1: Table S2).

\section{SNPs and level of lung function}

Subjects heterozygous for SNP rs4925 had a significantly higher $\mathrm{FEV}_{1}[23 \mathrm{ml}(0 ; 45)]$ and subjects heterozygous for $\mathrm{rs} 156699$ a significantly higher $\mathrm{FEV}_{1} / \mathrm{FVC}[0.3 \%$ $(0 ; 0.7)]$ than wild types. There were no other significant associations between genotype and lung function (Additional file 1: Table S3).

\section{Effect of interaction between GSTO SNPs and in utero ETS exposure on level of lung function}

Mean $\mathrm{FEV}_{1}$ levels were significantly different (i.e. higher with in utero ETS, and lower with daily and workplace ETS exposure) in subjects carrying both minor alleles for all four GSTO SNPs compared to wild type and heterozygote genotypes (Figure 2). Therefore we used a recessive genetic model in subsequent analyses. In utero ETS exposure interacted with all four GSTO SNPs and these interactions were associated with higher level of $\mathrm{FEV}_{1}$ level (Table 2), i.e. being homozygote for the minor alleles was associated with a higher $\mathrm{FEV}_{1}$ only in subjects that were exposed to ETS in utero. There was no association with $\mathrm{FEV}_{1} / \mathrm{FVC}$ (Additional file 1: Table S4). Associations were more pronounced in never smokers, except for SNP rs 156697 (Table 2). Most of these interactions remained significant after FDR correction for multiple testing.

\section{Effect of interaction between GSTO SNPs and adulthood ETS exposure on level of lung function}

Daily ETS exposure ( $\geq 1$ hour) interacted significantly with SNPs rs4925, rs1147611 and rs156699 and these interactions were associated with lower $\mathrm{FEV}_{1}$ level (Table 3). Workplace ETS interacted significantly with all four SNPs and these interactions were associated with lower $\mathrm{FEV}_{1}$ (Table 4). In other words, being homozygote for the minor alleles of the GSTO SNPs was associated with lower level of lung function only in subjects that were exposed to daily and workplace ETS exposure. Stratification by smoking status showed that the negative interaction effects between ETS exposure and the SNPs on FEV ${ }_{1}$ level were consistently more pronounced in never smokers (Tables 3 and 4). No significant interactions were found between daily and workplace ETS exposure and the GSTO SNPs on $\mathrm{FEV}_{1} /$ FVC in the whole group, or when stratified by smoking status (never/ever) (Additional file 1: Tables S5 and S6). All significant interactions of the GSTO SNPs with workplace ETS on level of $F E V_{1}$ remained significant after FDR correction for multiple testing, the interactions with daily ETS exposure did not remain significant. 


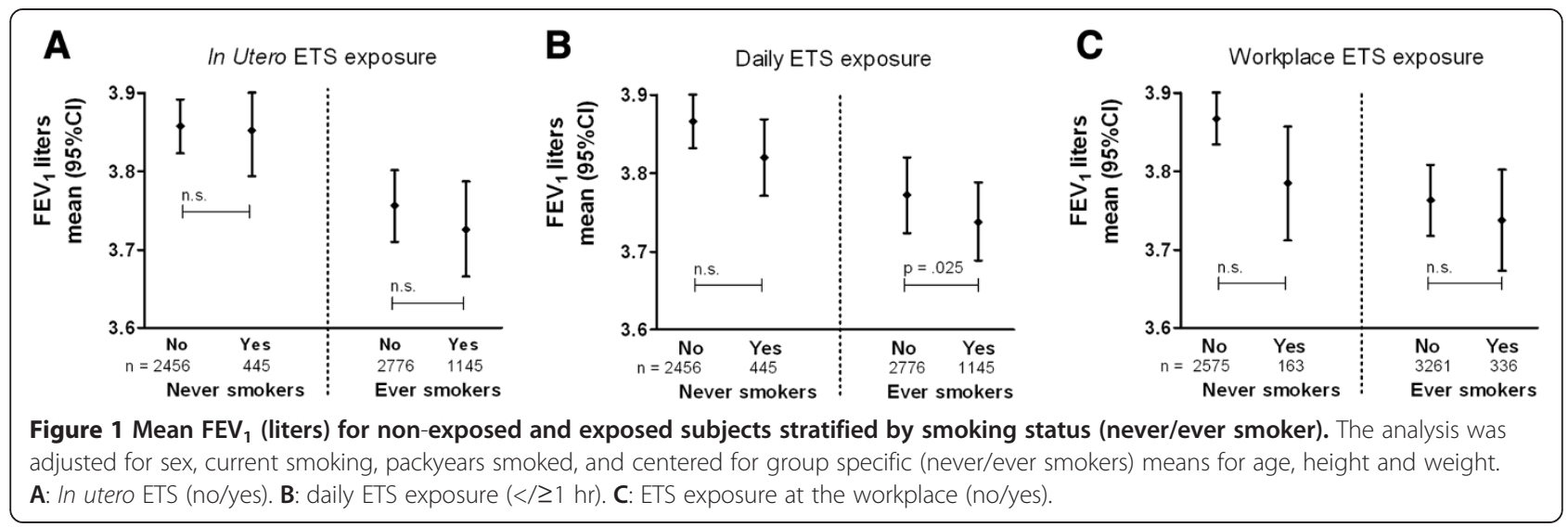

Verification of initial findings in the second sample

Population characteristics (Table 1) and genotype frequencies (Additional file 1: Table S1) were similar in the second (verification) and the first sample. Complete data was available for $\mathrm{n}=3914,4527$ and 4702 subjects for in utero, daily and workplace ETS respectively. Estimates for the negative associations of in utero, daily and workplace ETS exposure on $\mathrm{FEV}_{1}$ and $\mathrm{FEV}_{1} / \mathrm{FVC}$ in the verification sample, were in line with associations found in sample 1, yet did not all reach statistical significance (Additional file 1: Table S7). Associations between the heterozygote genotypes for rs4925 and rs156699 with $\mathrm{FEV}_{1}$ and $\mathrm{FEV}_{1} / \mathrm{FVC}$ respectively, found in sample 1 , could not be replicated in the second sample (Additional file 1: Table S3).

\section{Interaction GSTO SNPs with in utero ETS}

Similar to sample 1, GSTO2 SNP rs156697 significantly interacted with in utero ETS exposure and was associated with a higher level of $\mathrm{FEV}_{1}$ in sample 2 (Table 5). The other GSTO SNPs consistently had effects in the similar direction, yet without reaching statistical significance.

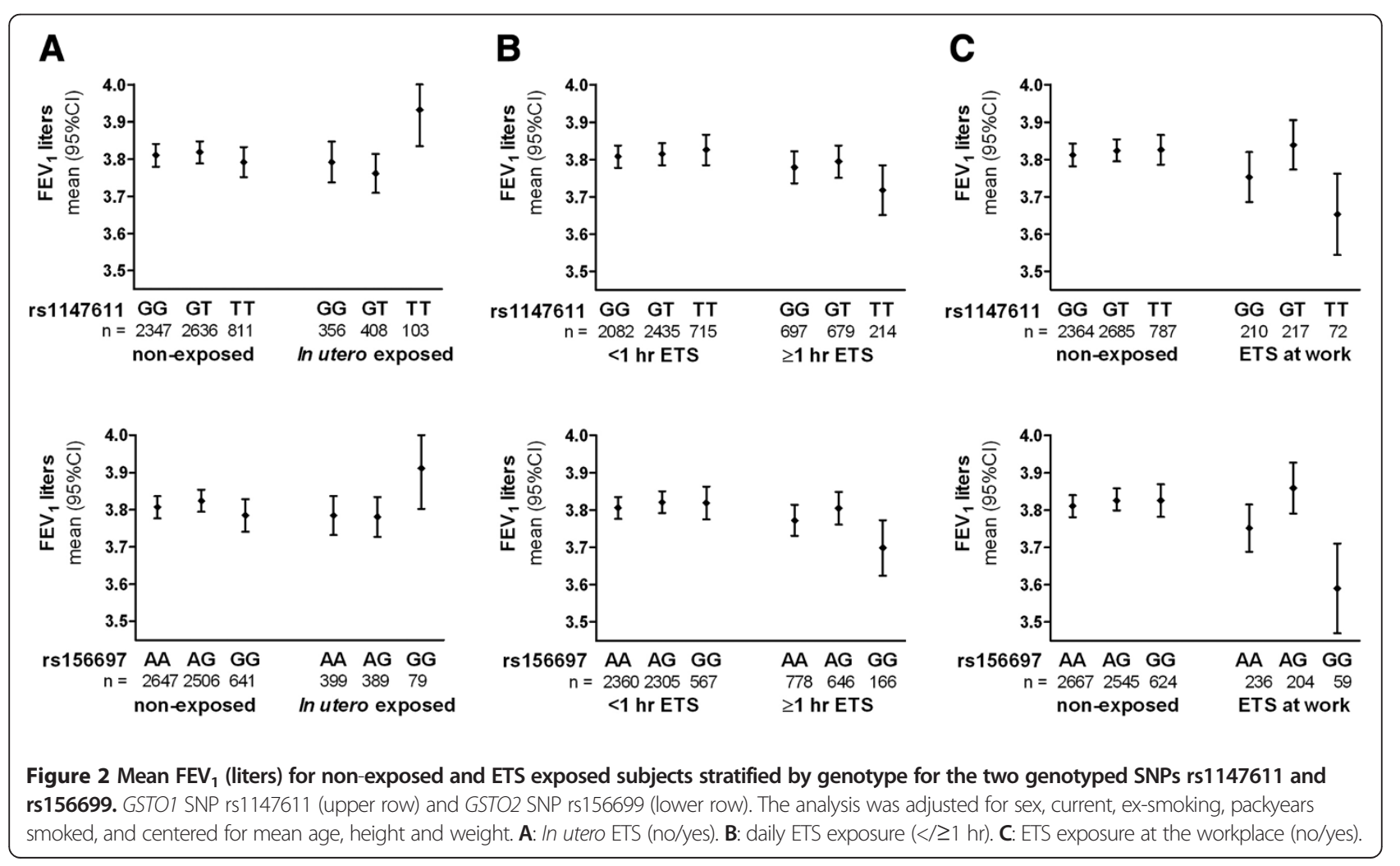


Table 2 Effects for in utero ETS exposure (no/yes), the SNPs, and the interaction of GSTO SNPs (recessive model) with in utero ETS exposure on FEV $_{1}$

\begin{tabular}{|c|c|c|c|c|}
\hline \multirow[b]{2}{*}{ Gene } & \multirow[b]{2}{*}{ Variable } & \multirow[b]{2}{*}{ All } & \multicolumn{2}{|l|}{ FEV1 (ml) b $(95 \% \mathrm{Cl})$} \\
\hline & & & Never smokers & Ever smokers \\
\hline & $\mathrm{N}$, in analysis & 6003 & 2576 & 3427 \\
\hline \multirow[t]{3}{*}{ GSTO1 } & In utero ETS & $-33(-69 ; 4)$ & $-25(-81 ; 32)$ & $-43(91 ; 5)$ \\
\hline & rs4925 & $-33(-77 ; 10)$ & $-1(65 ; 63)$ & $-58(-117 ; 1)$ \\
\hline & ETS*rs4925 & ${ }^{\$} 177(50 ; 305)^{* *}$ & $196(15 ; 376)^{*}$ & $161(-18 ; 340)$ \\
\hline \multirow[t]{3}{*}{ GSTO1 } & In utero ETS & $-40(-77 ;-2)^{*}$ & $-32(-89 ; 26)$ & $-51(-100 ;-2)^{*}$ \\
\hline & rs1147611 & $-22(-58 ; 14)$ & $6(-46 ; 58)$ & $-46(-96 ; 3)$ \\
\hline & ETS*rs1147611 & ${ }^{\$} 177(72 ; 283)^{* * *}$ & ${ }^{\$} 206(47 ; 365)^{*}$ & $166(25 ; 307)^{*}$ \\
\hline \multirow[t]{3}{*}{ GSTO2 } & In utero ETS & $-41(-78 ;-3)^{*}$ & $-28(-85 ; 30)$ & $-55(-104 ;-6)^{*}$ \\
\hline & rs156697 & $-28(-64 ; 9)$ & $9(-44 ; 62)$ & $-59(-110 ;-8)^{*}$ \\
\hline & ETS*rs156697 & ${ }^{\$} 198(90 ; 307)^{* * *}$ & $181(20 ; 342)^{*}$ & ${ }^{\$} 219(72 ; 366)^{* *}$ \\
\hline \multirow[t]{3}{*}{ GSTO2 } & In utero ETS & $-33(-70 ; 3)$ & $-24(-81 ; 32)$ & $-45(-93 ; 4)$ \\
\hline & rs156699 & $-30(-70 ; 10)$ & $-9(-66 ; 49)$ & $-48(-104 ; 7)$ \\
\hline & ETS*rs156699 & ${ }^{\$} 160(41 ; 278)^{* *}$ & $193(12 ; 374)^{*}$ & $143(-15 ; 300)$ \\
\hline
\end{tabular}

The linear regression model for the whole group was adjusted for sex, age, height, weight, current, ex-smoking and packyears smoked. Consequently we stratified by smoking status (never/ever) and adjusted for the other possible confounders.

${ }^{*}$ p-value $<0.05 * *$ p-value $<0.01 * *$ p-value $<0.001$.

\$significant after FDR correction for multiple testing.

Interaction GSTO SNPs with daily and workplace ETS exposure Analyses in the verification sample did not show any significant interaction or trend for interaction between the GSTO SNPs and daily ( $\geq 1$ hour) ETS exposure (Table 5). In line with findings in sample 1, there were clear interactions of the GSTO SNPs with workplace ETS exposure that were associated with lower level of $\mathrm{FEV}_{1}$, but these interactions were non-significant in sample 2 (Table 5). Full results of the (stratified) analyses in sample 2 can be found in Additional file 1: Tables S8, S9 and S10.

Overall, the directions of the interactions of in utero and workplace ETS exposure with the SNPs found in the second (verification) sample were in line with the first sample, but effect estimates were somewhat smaller and not always significant.

Table 3 Effects for daily ETS exposure $(</ \geq 1 \mathrm{hr})$, the SNPs, and the interaction of GSTO SNPs (recessive model) with daily ETS exposure on FEV 1

\begin{tabular}{|c|c|c|c|c|}
\hline \multirow[b]{2}{*}{ Gene } & \multirow[b]{2}{*}{ Variable } & \multirow[b]{2}{*}{ All } & \multirow{2}{*}{$\frac{\mathrm{FEV}_{1}(\mathrm{ml}) \mathrm{b}(95 \% \mathrm{Cl})}{\text { Never smokers }}$} & \multirow[b]{2}{*}{ Ever smokers } \\
\hline & & & & \\
\hline & $\mathbf{N}$, in analysis & 6822 & 2901 & 3921 \\
\hline \multirow[t]{3}{*}{ GSTO1 } & Daily ETS & $-27(-56 ; 3)$ & $-31(-79 ; 16)$ & $-28(-66 ; 10)$ \\
\hline & rs4925 & $61(-37 ; 49)$ & $67(6 ; 128)^{*}$ & $-46(-106 ; 15)$ \\
\hline & ETS*rs4925 & $-115(-209 ;-22)^{*}$ & $-153(-306 ; 0)$ & $-72(-192 ; 47)$ \\
\hline \multirow[t]{3}{*}{ GSTO1 } & Daily ETS & $-25(-55 ; 5)$ & $-28(-77 ; 22)$ & $-28(-67 ; 11)$ \\
\hline & rs1147611 & $15(-22 ; 51)$ & $56(5 ; 107)^{*}$ & $-24(-75 ; 28)$ \\
\hline & ETS*rs1147611 & $-83(-159 ;-7)^{*}$ & $-122(-247 ; 3)$ & $-45(-147 ; 52)$ \\
\hline \multirow[t]{3}{*}{ GSTO2 } & Daily ETS & $-29(-59 ; 1)$ & $-28(-77 ; 22)$ & $-34(-73 ; 5)$ \\
\hline & rs156697 & $6(-31 ; 43)$ & $57(5 ; 109)^{*}$ & $-40(-93 ; 12)$ \\
\hline & ETS*rs156697 & $-59(-137 ; 19)$ & $-127(-252 ;-1)^{*}$ & $-2(-104 ; 99)$ \\
\hline \multirow[t]{3}{*}{ GSTO2 } & Daily ETS & $-26(-56 ; 3)$ & $-29(-78 ; 19)$ & $-28(-66 ; 10)$ \\
\hline & rs156699 & $6(-35 ; 46)$ & $44(-12 ; 100)$ & $-29(-86 ; 28)$ \\
\hline & ETS*rs156699 & $-94(-178 ;-10)^{*}$ & $-133(-268 ; 2)$ & $-56(-165 ; 54)$ \\
\hline
\end{tabular}

The linear regression model for the whole group was adjusted for sex, age, height, weight, current, ex-smoking and packyears smoked. Consequently we stratified by smoking status (never/ever) and adjusted for the other possible confounders.

p-value< 0.05 .

There were no significant effects after FDR correction for multiple testing. 
Table 4 Effects for workplace ETS exposure (n/y), the SNPs, and the interaction of GSTO SNPs (recessive model) with workplace ETS exposure on FEV 1

\begin{tabular}{|c|c|c|c|c|}
\hline \multirow[b]{2}{*}{ Gene } & \multirow[b]{2}{*}{ Variable } & \multirow[b]{2}{*}{ All } & \multirow{2}{*}{$\frac{\mathrm{FEV}_{1}(\mathrm{ml}) \mathrm{b}(95 \% \mathrm{Cl})}{\text { Never smokers }}$} & \multirow[b]{2}{*}{ Ever smokers } \\
\hline & & & & \\
\hline & $\mathrm{N}$, in analysis & 7149 & 3051 & 4098 \\
\hline \multirow[t]{3}{*}{ GSTO1 } & Workplace ETS & $-26(-71 ; 20)$ & $-51(-126 ; 25)$ & $-17(-73 ; 40)$ \\
\hline & rs4925 & $8(-34 ; 50)$ & $78(17 ; 138)$ & $-48(-105 ; 9)$ \\
\hline & ETS*rs4925 & ${ }^{\$}-173(-313 ;-33)^{*}$ & \$ $-281(-498 ;-64)^{*}$ & $-84(-268 ; 100)$ \\
\hline \multirow[t]{3}{*}{ GSTO1 } & Workplace ETS & $-22(-68 ; 25)$ & $-41(-117 ; 36)$ & $-15(-73 ; 43)$ \\
\hline & rs1147611 & $8(-27 ; 42)$ & $49(0 ; 99)^{\#}$ & $-29(-78 ; 19)$ \\
\hline & ETS*rs1147611 & ${ }^{\$}-151(-272 ;-31)^{*}$ & ${ }^{\$}-286(-486 ;-87)^{* *}$ & $-65(-218 ; 87)$ \\
\hline \multirow[t]{3}{*}{ GSTO2 } & Workplace ETS & $-21(-67 ; 25)$ & $-41(-118 ; 36)$ & $-14(-72 ; 44)$ \\
\hline & rs156697 & $8(-28 ; 44)$ & $50(-1 ; 100)$ & $-29(-79 ; 20)$ \\
\hline & ETS*rs156697 & ${ }_{-170}(-295 ;-46)^{* *}$ & $-287(-486 ;-88)^{* *}$ & $-84(-245 ; 77)$ \\
\hline \multirow[t]{3}{*}{ GSTO2 } & Workplace ETS & $-17(-63 ; 28)$ & $-41(-117 ; 35)$ & $-9(-66 ; 48)$ \\
\hline & rs156699 & $6(-32 ; 45)$ & $43(-12 ; 98)$ & $-26(-79 ; 28)$ \\
\hline & ETS*rs156699 & ${ }^{\$}-218(-349 ;-87)^{* *}$ & $\$-318(-525 ;-111)^{* *}$ & $-140(-311 ; 30)$ \\
\hline
\end{tabular}

The linear regression model for the whole group was adjusted for sex, age, height, weight, current, ex-smoking and packyears smoked. Consequently we stratified by smoking status (never/ever) and adjusted for the other possible confounders.

p-value $<0.05{ }^{* *} \mathrm{p}$-value $<0.01$

\$significant after FDR correction for multiple testing.

\section{Discussion}

\section{Main finding}

This study is the first to show that GSTO SNPs interact with ETS exposure on $\mathrm{FEV}_{1}$, findings that were significant after FDR correction for multiple testing and replicated in the second (verification) sample or showed similar directions of effects. Interestingly, interactions were in opposite directions for ETS exposure in utero and during adulthood.
Results in relation to other studies

Smoking during pregnancy has been shown to reduce tidal flow-volume ratios in healthy newborn babies $[4,5]$ and to reduce small airway flows in school age children [29]. We found no significant effect of in utero ETS exposure on level of $\mathrm{FEV}_{1}$ in adulthood in both our study samples, which does not exclude that effects might be present when studying more specifically small airway

Table 5 Verification of the interaction of GSTO SNPs (recessive model) with different types of ETS exposure on FEV in $_{1}$ sample 2

\begin{tabular}{|c|c|c|c|c|}
\hline \multirow[b]{2}{*}{ Gene } & \multirow[b]{2}{*}{ Variable } & \multirow[b]{2}{*}{ In utero ETS } & \multirow{2}{*}{$\frac{\mathrm{FEV}_{1}(\mathrm{ml}) \mathrm{b}(95 \% \mathrm{Cl})}{\text { Daily ETS }}$} & \multirow[b]{2}{*}{ Workplace ETS } \\
\hline & & & & \\
\hline & $\mathrm{N}$, in analysis & 3914 & 4527 & 4702 \\
\hline \multirow[t]{3}{*}{ GSTO1 } & ETS & $-45(-91 ; 1)$ & $-41(-78 ;-4)^{*}$ & $-40(-98 ; 18)$ \\
\hline & rs4925 & $11(-43 ; 65)$ & $15(-36 ; 66)$ & $33(-17 ; 83)$ \\
\hline & ETS*rs4925 & $111(-32 ; 253)$ & $25(-93 ; 142)$ & $-163(-390 ; 65)$ \\
\hline \multirow[t]{3}{*}{ GSTO1 } & ETS & $-49(-96 ;-1)^{*}$ & $-40(-78 ;-2)^{*}$ & $-40(-100 ; 20)$ \\
\hline & rs1147611 & $4(-40 ; 47)$ & $21(-21 ; 63)$ & $26(-15 ; 67)$ \\
\hline & ETS*rs1147611 & $94(-22 ; 211)$ & $5(-89 ; 98)$ & $-87(-254 ; 81)$ \\
\hline \multirow[t]{3}{*}{ GSTO2 } & ETS & $-52(-99 ;-5)^{*}$ & $-41(-79 ;-4)^{*}$ & $-38(-98 ; 21)$ \\
\hline & rs156697 & $2(-42 ; 46)$ & $17(-25 ; 59)$ & $28(-13 ; 69)$ \\
\hline & ETS*rs156697 & $119(0 ; 237)^{*}$ & $17(-79 ; 113)$ & $-99(-269 ; 70)$ \\
\hline \multirow[t]{3}{*}{ GSTO2 } & ETS & $-46(-92 ; 1)$ & $-40(-78 ;-3)^{*}$ & $-42(-101 ; 17)$ \\
\hline & rs156699 & $-9(-58 ; 39)$ & $0(-46 ; 47)$ & $10(-35 ; 56)$ \\
\hline & ETS*rs156699 & $106(-29 ; 241)$ & $9(-97 ; 115)$ & $-101(-292 ; 91)$ \\
\hline
\end{tabular}

Effects for in utero ETS exposure (no/yes), daily ETS exposure $(</ \geq 1 \mathrm{hr}$ ), workplace ETS exposure (no/yes), the SNPs, and the interaction of GSTO SNPs (recessive model) with different types of ETS exposure on $\mathrm{FEV}_{1}$ in sample 2 (verification). The linear regression model for the whole group was adjusted for sex, age, height, weight, current, ex-smoking and packyears smoked.

${ }^{*} \mathrm{p}$-value $<0.05$. 
dimensions as derived in school age children [29]. In line with other studies investigating effects of ETS exposure during adulthood [6,7], we found daily and workplace ETS to be associated with lower levels of $\mathrm{FEV}_{1}$, and these effects were more pronounced in never smokers. Our effect estimate of a $45 \mathrm{ml}$ lower $\mathrm{FEV}_{1}$ level with daily ETS exposure in never smokers was comparable with the $35 \mathrm{ml}(-66 ;-4)$ reduced $\mathrm{FEV}_{1}$ level with daily ETS exposure of 1 to 4 hours in never smokers from the European Community Respiratory Health Survey (ECRHS) [7].

The homozygote mutant genotype for SNP rs156697 was not associated with the level of $\mathrm{FEV}_{1}$ in our sample, but there was a significant interaction with in utero ETS exposure that was associated with higher level of $\mathrm{FEV}_{1}$. This was a robust finding that remained significant after FDR correction for multiple testing and was moreover significantly replicated in the verification sample. Interactions between the other three SNPs and in utero ETS exposure showed clear trends for an association with higher level of $\mathrm{FEV}_{1}$ in both samples but only reached significance in the first sample. Interestingly, the homozygote mutant genotypes for SNPs rs4925, rs1147611, rs156699 significantly interacted with daily ETS exposure, and all SNPs (rs4925, rs1147611, rs156697, and rs156699) significantly interacted with workplace ETS exposure and were associated with lower level of $\mathrm{FEV}_{1}$ in the first sample. The interactions with workplace ETS exposure remained significant after FDR correction for multiple testing and showed a clear trend for interaction in the similar direction in the verification sample. These latter results support previous findings that GSTO2 is a risk gene for lower levels of $\mathrm{FEV}_{1}$ and $\mathrm{FVC}$ [12].

How can we reconcile that exposure to (harmful) ETS in utero does not result in lower but higher adult level of lung function in subjects who are homozygote mutant for the GSTO "risk" alleles, whereas adult ETS exposure in these individuals associates with lower lung function? First, exposure to ETS in utero likely leads to exposure to different substances and concentrations of substances than 'direct' inhalation of ETS. It is conceivable that substances of ETS will be 'filtered' by the maternal lung and circulation, the placenta and fetal circulation. In addition, it is also conceivable that chronic ETS during pregnancy induces maternal changes that are important for lung growth. For example, it is well-known that nicotine inhaled with cigarette smoking stimulates secretion of growth hormone in humans [30]. This is particularly interesting because growth hormone has been shown to stimulate lung growth as well as lung development during the period of alveolarization [31].

Another explanation relates to exposure to ETS taking place in completely different periods of the life-span. Different biochemical and biological processes are involved in lung development in utero, lung growth in childhood and early adulthood, and lung function decline in adulthood. ETS may therefore cause differential and even contradictory effects in different periods of life. For example, oxidative stress in utero possibly does not only damage, but is additionally necessary for cell apoptosis during lung morphogenesis. A recent study showed that risk genotypes for the non-synonymous SNPs rs4925 (Ala140Asp) in GSTO1 and rs156697 (Asn142Asp) in GSTO2 reduce GSTO2 expression levels, leading to accumulation of oxidative damage [32]. Increased oxidant levels may contribute to cell apoptosis and subsequently better airway branching in utero, with positive effects on $\mathrm{FEV}_{1}$ levels. This may contrast to adult life where airway branching has stopped and oxidative stress has predominantly negative effects, i.e. induced epithelial and endothelial cell damage and apoptosis that may contribute to airway wall and/or lung tissue fibrosis and subsequently a lower level of $\mathrm{FEV}_{1}$. Obviously, different biological processes and pathways underlie the differential effects of ETS in utero versus later in life. However, all given explanations are speculative and merit further research.

Generally we found that the interactions between daily and workplace ETS exposure and the GSTO SNPs were more pronounced in the never smokers. For in utero ETS exposure this difference was less evident. These findings might suggest that among ever smokers the effects are somewhat overruled by the effects of personal smoking, that may damage the lung by similar mechanisms yet with higher doses. We were not able to test if the interaction between GSTO SNPs and ETS was significantly different between the never and ever smokers since we did not have enough study power for testing this three-way interaction between smoking status and GSTO SNPs and ETS.

We did not find consistent significant interaction effects of the GSTO SNPs and ETS exposure on $\mathrm{FEV}_{1} / \mathrm{FVC}$. Since the interactions were negatively associated with $\mathrm{FEV}_{1}$ but not with $\mathrm{FEV}_{1} / \mathrm{FVC}$, in an additional analysis we investigated effects on FVC. In line with effects on $\mathrm{FEV}_{1}$, all four GSTO SNPs interacted positively with in utero ETS exposure and negatively with workplace ETS exposure on FVC level. Daily ETS exposure interacted negatively with the GSTO SNPs on FVC, but these associations were not significant. These findings suggest restrictive rather than obstructive effects on lung function.

\section{Strengths and limitations}

The extensive standardized characterization of the LifeLines population and the large sample size provided the unique opportunity to investigate gene-by-environment interactions. A major strength was the inclusion of a large verification sample that is very similar to the discovery sample. Since the verification sample was somewhat smaller than the identification sample, its power might have been too 
low to replicate the significant associations, but we observed clear trends in similar directions. Haplotype analysis did not provide additional information and was therefore not shown. In the current study we have adjusted for traditional covariates related to level of lung function. Additional adjustment for highest obtained level of education, as proxy for socio-economic status, ever having had a cardiovascular event or bronchodilator use did not change our results.

A limitation of our study might be the cross-sectional design with rather crude assessment of ETS exposure, without data on lifetime exposure and quantitative measurement of workplace exposure. Objective measures of exposure to environmental tobacco smoking such as cotinine levels in serum or urine were unfortunately not available. However, the exact questions as defined in the ECRHS surveys were used in our study, and these questions were validated in an Italian subsample of the ECRHS. The question about the number of hours that a person is exposed to other people's tobacco smoke showed a modest correlation with serum cotinine levels, with a clear dose-response effect between the number of hours and cotinine levels [33]. Notwithstanding this, it should be acknowledged that using self-reports may lead to recall bias, i.e. people experiencing respiratory illness are more likely to recall and report ETS exposure.

\section{Conclusions}

Our data show that polymorphisms in GSTO genes, involved in oxidative stress pathways and detoxification of xenobiotic substances interact with ETS exposure both in utero and in adulthood and significantly affect the level of $\mathrm{FEV}_{1}$.

\section{Additional file}

Additional file 1: Figure S1. $L D$ plot showing $R^{2}$ between genotyped (rs1147611 and rs156699) and imputed (rs4925 and rs156697) GSTO1 and GSTO2 SNPs in sample 1. Table S1. Genotype frequencies and minor allele frequency (MAF) for the four tagging SNPs in the GSTO1-2 cluster in samples 1 and 2. Table S2. Associations between ETS exposure and lung function level in sample 1. Table S3. Associations between genotypes and lung function in samples 1 and 2. Table S4. Effects for in utero ETS exposure (no/yes), the SNPS, and the interaction of GSTO SNPs (recessive model) with in utero ETS exposure on $\mathrm{FEV}_{1} / \mathrm{FVC}(\%)$ in sample 1. Table S5. Effects for daily ETS exposure $(</ \geq 1 \mathrm{hr})$, the SNPS, and the interaction of GSTO SNPS (recessive model) with daily ETS exposure on $\mathrm{FEV}_{1} / \mathrm{FVC}(\%)$ in sample 1. Table S6. Effects for workplace ETS exposure (n/y), the SNPs, and the interaction of GSTO SNPS (recessive model) with workplace ETS exposure on $\mathrm{FEV}_{1} / \mathrm{FVC}(\%)$ in sample 1. Table S7. Verification: Associations between ETS exposure and lung function level (FEV ${ }_{1}$ and $\left.F E V_{1} / F V C(\%)\right)$ in sample 2. Table S8. Verification: Effects for in utero ETS exposure (no/yes), the SNPs, and the interaction of GSTO SNPs (recessive model) with in utero ETS exposure on $\mathrm{FEV}_{1}$ in sample 2. Table S9. Verification: Effects for daily ETS exposure $(</ \geq 1 \mathrm{hr})$, the SNPS, and the interaction of GSTO SNPS (recessive model) with daily ETS exposure on $\mathrm{FEV}_{1}$ in sample 2. Table S10. Verification: Effects for workplace ETS exposure (n/y), the SNPs, and the interaction of GSTO SNPs (recessive model) with workplace ETS exposure on $\mathrm{FEV}_{1}$ in sample 2.

\section{Abbreviations}

ETS: Environmental tobacco smoke; SNP: Single nucleotide polymorphism; GST: Glutathione S-Transferase; GSTO: Glutathione S-Transferase Omega; COPD: Chronic obstructive pulmonary disease; CF: Cystic fibrosis;

$\mathrm{FEV}_{1}$ : Forced expiratory volume in one second; FVC: Forced vital capacity; FDR: False discovery rate.

\section{Competing interests}

The University of Groningen has received money for NHT ten Hacken regarding an unrestricted educational grant for research from Chiesi, GSK, and Boehringer. The University of Groningen has received money for DS Postma regarding an unrestricted educational grant for research from AstraZeneca, Chiesi, GSK. Travel of to ERS and/or ATS has been partially funded by AstraZeneca, Chiesi, GSK, Nycomed. Fees for consultancies were given to the University of Groningen by AZ, Boehringer Ingelheim, Chiesi, GSK, Nycomed and TEVA. None of the other authors has conflicts of interest related to this work.

\section{Authors' contributions}

$\mathrm{KdJ}$ participated in the study design, analyzed the data and wrote the manuscript. HMB, DSP and JMV obtained funding, determined the study design, participated in the analysis and interpretation of data, and critically supervised writing of the manuscript. NTH has significantly contributed to the results, the discussion and writing of the manuscript. All authors read and approved the final manuscript.

\section{Acknowledgements}

We thank Behrooz Alizadeh, Annemieke Boesjes, Marcel Bruinenberg, Noortje Festen, Pim van der Harst, Ilja Nolte, Lude Franke, Mitra Valimohammadi for their help in creating the GWAS database, and Rob Bieringa, Joost Keers, René Oostergo, Rosalie Visser, Judith Vonk for their work related to datacollection and validation. The authors are grateful to the study participants, the staff from the LifeLines Cohort Study and Medical Biobank Northern Netherlands, and the participating general practitioners and pharmacists.

\section{Funding}

Research Institute for Drug Exploration (GUIDE), University Medical Center Groningen, University of Groningen, the Netherlands. The LifeLines Cohort Study, and generation and management of GWAS genotype data for the LifeLines Cohort Study is supported by the Netherlands Organization of Scientific Research NWO (grant 175.010.2007.006), the Economic Structure Enhancing Fund (FES) of the Dutch government, the Ministry of Economic Affairs, the Ministry of Education, Culture and Science, the Ministry for Health, Welfare and Sports, the Northern Netherlands Collaboration of Provinces (SNN), the Province of Groningen, University Medical Center Groningen, the University of Groningen, Dutch Kidney Foundation and Dutch Diabetes Research Foundation. The sponsors had no role in the study design, data collection, analysis and interpretation, or in writing and submitting the manuscript.

\section{Author details}

'University of Groningen, University Medical Center Groningen (UMCG), Department of Epidemiology, Groningen, the Netherlands. ${ }^{2}$ University of Groningen, University Medical Center Groningen (UMCG), Department of Pulmonology, Groningen, the Netherlands. ${ }^{3}$ University Medical Center Groningen, Groningen Research Institute for Asthma and COPD (GRIAC), Groningen, the Netherlands.

Received: 2 April 2013 Accepted: 15 July 2013

Published: 9 August 2013

\section{References}

1. Hospers JJ, Schouten JP, Weiss ST, Postma DS, Rijcken B: Eosinophilia is associated with increased all-cause mortality after a follow-up of 30 years in a general population sample. Epidemiology 2000, 11:261-268.

2. Knuiman MW, James AL, Divitini ML, Ryan G, Bartholomew HC, Musk AW: Lung function, respiratory symptoms, and mortality: results from the Busselton Health Study. Ann Epidemiol 1999, 9:297-306.

3. Doruk S, Ozyurt H, Inonu H, Erkorkmaz U, Saylan O, Seyfikli Z: Oxidative status in the lungs associated with tobacco smoke exposure. Clin Chem Lab Med 2011, 49:2007-2012. 
4. Lodrup Carlsen KC, Jaakkola JJ, Nafstad P, Carlsen KH: In utero exposure to cigarette smoking influences lung function at birth. Eur Respir J 1997, 10:1774-1779.

5. Stick SM, Burton PR, Gurrin L, Sly PD, LeSouf PN: Effects of maternal smoking during pregnancy and a family history of asthma on respiratory function in newborn infants. Lancet 1996, 348:1060-1064.

6. Eisner M: Environmental tobacco smoke exposure and pulmonary function among adults in NHANES III: impact on the general population and adults with current asthma. Environ Health Perspect 2002, 110:765-770.

7. Janson C, Chinn S, Jarvis D, Zock J, Torén K, Burney P: Effect of passive smoking on respiratory symptoms, bronchial responsiveness, lung function, and total serum IgE in the European Community Respiratory Health Survey: a cross-sectional study. Lancet 2001, 358:2103-2109.

8. Leuenberger P, Schwartz J, Ackermann Liebrich U, Blaser K, Bolognini G, Bongard JP, Brandli O, Braun P, Bron C, Brutsche M: Passive smoking exposure in adults and chronic respiratory symptoms (SAPALDIA Study). Swiss Study on Air Pollution and Lung Diseases in Adults, SAPALDIA Team. Am J Respir Crit Care Med 1994, 150:1222-1228.

9. Simoni M, Baldacci S, Puntoni R, Pistelli F, Farchi S, Lo Presti E, Pistelli R, Corbo G, Agabiti N, Basso S, Matteelli G, Di Pede F, Carrozzi L, Forastiere F, Viegi G: Respiratory symptoms/diseases and environmental tobacco smoke (ETS) in never smoker Italian women. Respir Med 2007, 101:531-538.

10. Eisner M, Balmes J, Katz P, Trupin L, Yelin E, Blanc P: Lifetime environmental tobacco smoke exposure and the risk of chronic obstructive pulmonary disease. Environ Health 2005, 4:7-7.

11. Yin P, Jiang CQ, Cheng KK, Lam TH, Lam KH, Miller MR, Zhang WS, Thomas GN, Adab P: Passive smoking exposure and risk of COPD among adults in China: the Guangzhou Biobank Cohort Study. Lancet 2007 370:751-757.

12. Wilk JB, Walter RE, Laramie JM, Gottlieb DJ, O'Connor GT: Framingham Heart Study genome-wide association: results for pulmonary function measures. BMC Med Genet 2007, 8(1):8.

13. Eaton $\mathrm{DL}$, Bammler TK: Concise review of the glutathione S-transferases and their significance to toxicology. Toxicol Sci 1999, 49:156-164.

14. Hayes JD, Flanagan JU, Jowsey IR: Glutathione Transferases. Annu Rev Pharmacol Toxicol 2005, 45:51-88.

15. Kabesch M, Hoefler C, Carr D, Leupold W, Weiland SK, von Mutius E: Glutathione $S$ transferase deficiency and passive smoking increase childhood asthma. Thorax 2004, 59:569-573.

16. Schultz EN, Devadason SG, Khoo SK, Zhang G, Bizzintino JA, Martin AC, Goldblatt J, Laing IA, Le Souef PN, Hayden CM: The role of GSTP1 polymorphisms and tobacco smoke exposure in children with acute asthma. J Asthma 2010, 47:1049-1056.

17. Breton CV, Vora H, Salam MT, Islam T, Wenten M, Gauderman WJ, Van Den Berg D, Berhane K, Peters JM, Gilliland FD: Variation in the GST mu Locus and tobacco smoke exposure as determinants of childhood lung function. Am J Respir Crit Care Med 2009, 179:601-607.

18. Board PG, Coggan M, Chelvanayagam G, Easteal S, Jermiin LS, Schulte GK, Danley DE, Hoth LR, Griffor MC, Kamath AV, Rosner MH, Chrunyk BA Perregaux DE, Gabel CA, Geoghegan KF, Pandit J: Identification, characterization, and crystal structure of the omega class glutathione transferases. J Biol Chem 2000, 275:24798-24806.

19. Board PG: The omega-class glutathione transferases: structure, function, and genetics. Drug Metab Rev 2011, 43:226-235.

20. Whitbread AK, Tetlow N, Eyre HJ, Sutherland GR, Board PG: Characterization of the human Omega class glutathione transferase genes and associated polymorphisms. Pharmacogenetics 2003, 13:131-144.

21. Laliberte RE, Perregaux DG, Hoth LR, Rosner PJ, Jordan CK, Peese KM, Eggler JF, Dombroski MA, Geoghegan KF, Gabel CA: Glutathione S-Transferase Omega 1-1 is a target of cytokine release inhibitory drugs and may be responsible for their effect on interleukin-1 $\beta$ posttranslational processing. J Biol Chem 2003, 278:16567-16578.

22. Pauwels NS, Bracke KR, Dupont LL, Van Pottelberge GR, Provoost S, Vanden Berghe T, Vandenabeele P, Lambrecht BN, Joos GF, Brusselle GG: Role of IL-1 $a$ and the Nlrp3/caspase-1/IL-1 $\beta$ axis in cigarette smoke-induced pulmonary inflammation and COPD. Eur Respir J 2011, 38:1019-1028.

23. Levy H, Murphy A, Zou F, Gerard C, Klanderman B, Schuemann B, Lazarus R, Garca KC, Celedn J, Drumm M, Dahmer M, Quasney M, Schneck K, Reske M, Knowles M, Pier G, Lange C, Weiss S: IL1B polymorphisms modulate cystic fibrosis lung disease. Pediatr Pulmonol 2009, 44:580-593.
24. Harju TH, Peltoniemi MJ, Rytila PH, Soini Y, Salmenkivi KM, Board PG, Ruddock LW, Kinnula VL: Glutathione S-transferase omega in the lung and sputum supernatants of COPD patients. Respir Res 2007, 8:48.

25. Yanbaeva DG, Wouters EF, Dentener MA, Spruit MA, Reynaert NL: Association of glutathione-S-transferase omega haplotypes with susceptibility to chronic obstructive pulmonary disease. Free Radic Res 2009, 43:738-743.

26. Stolk R, Rosmalen JGM, Postma D, de Boer R, Navis G, Slaets JPJ, Ormel J, Wolffenbuttel BHR: Universal risk factors for multifactorial diseases: LifeLines: a three-generation population-based study. Eur J Epidemiol 2008, 23:67-74.

27. Benjamini $Y$, Hochberg $Y$ : Controlling the false discovery rate: a practical and powerful approach to multiple testing. J R Statist Soc B 1995, 57:289-300.

28. Quanjer PH, Tammeling GJ, Cotes JE, Pedersen OF, Peslin R, Yernault JC: Lung volumes and forced ventilatory flows. Report Working Party Standardization of Lung Function Tests, European Community for Steel and Coal. Official Statement of the European Respiratory Society. Eur Respir J Suppl 1993, 16:5-40.

29. Gilliland FD, Berhane K, McConnell R, Gauderman WJ, Vora H, Rappaport EB, Avol E, Peters JM: Maternal smoking during pregnancy, environmenta tobacco smoke exposure and childhood lung function. Thorax 2000, 55:271-276

30. Coiro V, Volpi R, Stella A, Cataldo S, Giumelli C, Maccanelli F, Araldi A Chiodera P: Naloxone decreases the inhibitory effect of somatostatin on $\mathrm{GH}$ release induced by cigarette smoking in man. J Neural Transm 2011, 118:1173-1175.

31. Beyea JA, Olson DM, Harvey S: Growth hormone (GH) action in the developing lung: changes in lung proteins after adenoviral $\mathrm{GH}$ overexpression. Dev Dyn 2005, 234:404-412.

32. Allen M, Zou F, Chai H, Younkin C, Miles R, Nair A, Crook J, Pankratz VS, Carrasquillo M, Rowley C, Nguyen T, Ma L, Malphrus K, Bisceglio G, Ortolaza A, Palusak R, Middha S, Maharjan S, Georgescu C, Schultz D, Rakhshan F, Kolbert C, Jen J, Sando S, Aasly J, Barcikowska M, Uitti R, Wszolek Z, Ross O, Petersen R, Graff Radford N, Dickson D, Younkin S, Ertekin-Taner N: Glutathione S-transferase omega genes in Alzheimer and Parkinson disease risk, age-at-diagnosis and brain gene expression: an association study with mechanistic implications. Mol neurodegener 2012, 7:13-13.

33. Olivieri M, Poli A, Zuccaro P, Ferrari M, Lampronti G, de Marco R, Lo Cascio $\checkmark$, Pacifici R: Tobacco smoke exposure and serum cotinine in a random sample of adults living in Verona, Italy. Arch Environ Health 2002 57:355-359.

doi:10.1186/1465-9921-14-83

Cite this article as: de Jong et al:: GST-omega genes interact with environmental tobacco smoke on adult level of lung function. Respiratory Research 2013 14:83.

\section{Submit your next manuscript to BioMed Central and take full advantage of:}

- Convenient online submission

- Thorough peer review

- No space constraints or color figure charges

- Immediate publication on acceptance

- Inclusion in PubMed, CAS, Scopus and Google Scholar

- Research which is freely available for redistribution 